\title{
The North Inlet marsh - estuarine ecosystem: A conceptual approach
}

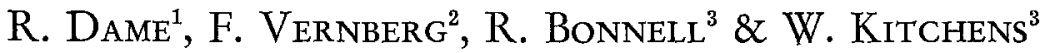 \\ Belle W. Baruch Institute for Marine Biology and Coastal Research, \\ ${ }^{1}$ Coastal Carolina College of University of South Carolina; Conway, \\ 2 Department of Biology, University of South Carolina; Columbia, \\ and \\ ${ }^{3}$ College of Engineering, University of South Carolina; Columbia, S.C., USA
}

\begin{abstract}
The North Inlet marsh - estuarine ecosystem (located at South Carolina, USA) is described via three sub-models: intertidal, benthic - subtidal and water column. The principal storage compartments and fluxes of energy are defined for each submodel. A detailed example of the intertidal oyster subsystem of the intertidal submodel is described. The biological components of the oyster community are shown to be stable and a linear systems model of the oyster community is developed. A $1 \%$ sensitivity analysis of the intertidal oyster model affords some order in which aspects of the oyster community should be studied.
\end{abstract}

\section{INTRODUCTION}

Estuaries and their surrounding marshlands are invaluable natural resources. These areas have served as centers of population and are heavily utilized for industrial development, shipping, fishing, and recreation. Furthermore, such usage is destined to increase in the future, with the wholly predictable result of increased competition for this limited natural resource. Estuaries already have been exploited to varying degrees; in some, almost the total biota has been ruined. Despite recognition that estuaries are not an unlimited resource, only recently have integrated scientific studies leading to the development of predictive models for multiple coastal zone use strategies begun to take place. Such integrated studies, rather than isolated investigations of individual species, are necessary for effective pollution control and long term management of the estuarine ecosystem. In particular, production energetics, and the mechanisms of various dynamic processes as influenced by environmental perturbations are poorly understood, although knowledge of these factors has obvious economic and scientific values.

This paper summarized portions of our study of the dynamics of a relatively undisturbed marsh-estuarine ecosystem. The objectives of these investigations are: (1) to understand better the dynamics of marsh-estuarine ecosystems through in- 
tegrative research, and (2) to be able to predict the consequences of technological and societal changes on estuaries.

The area investigated is the North Inlet Estuary located adjacent to the Belle W. Baruch Foundation property in Georgetown County, South Carolina, USA (Fig. 1). The specific study area is approximately $6 \mathrm{~km} \times 2.4 \mathrm{~km}$ and encompasses

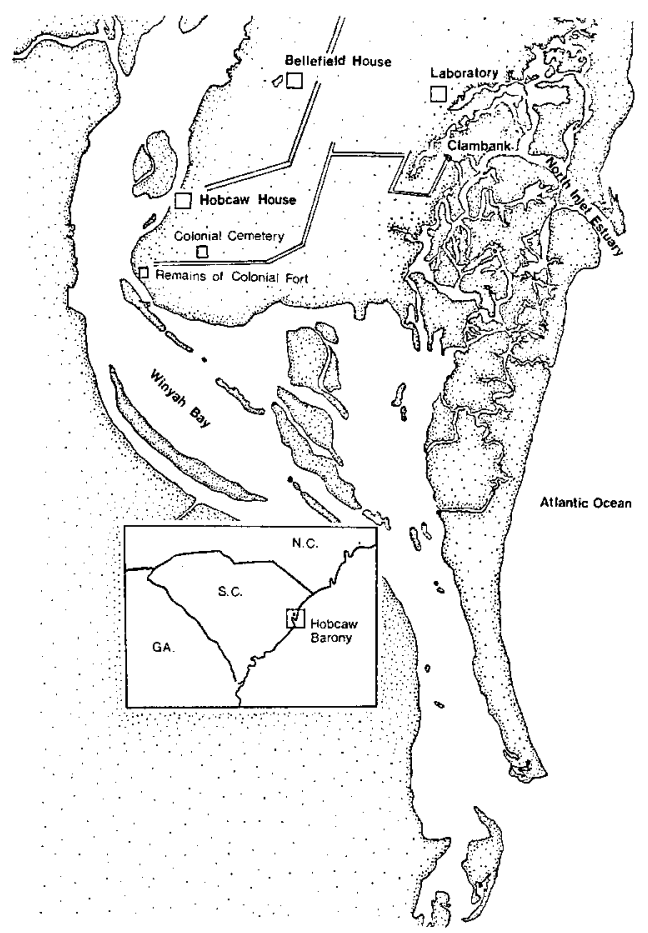

Fig. 1: The exact location of the particular habitats in the North Inlet Marsh-estuarine system

$14.4 \mathrm{~km}^{2}$ of marshland, chiefly dominated by Spartina alterniflora. Numerous creeks are found, and they represent various substrates such as mud, sand, or shell. Extensive and varied intertidal habitats exist, with oyster beds and reefs being very prominent.

THE NORTH INLET MODEL

\section{Subsystems}

Initially a comprehensive conceptual model of energy flow was formulated by our research team. For ease of comprehension this conceptual model was divided into three subsystems:

(1) The water column defined as the aqueous environment located above the 
bottoms of the benthic subtidal zone and the intertidal marsh zone, and the upper most boundary being the air-water interface (Fig. 2).

(2) The intertidal zone is the benthic region extending landward from the lower limit of the distribution of creek bank oysters (Crassostrea virginica), siphon tubes of the stout razor clam (Tagelus plebeius), and immediately above the upper

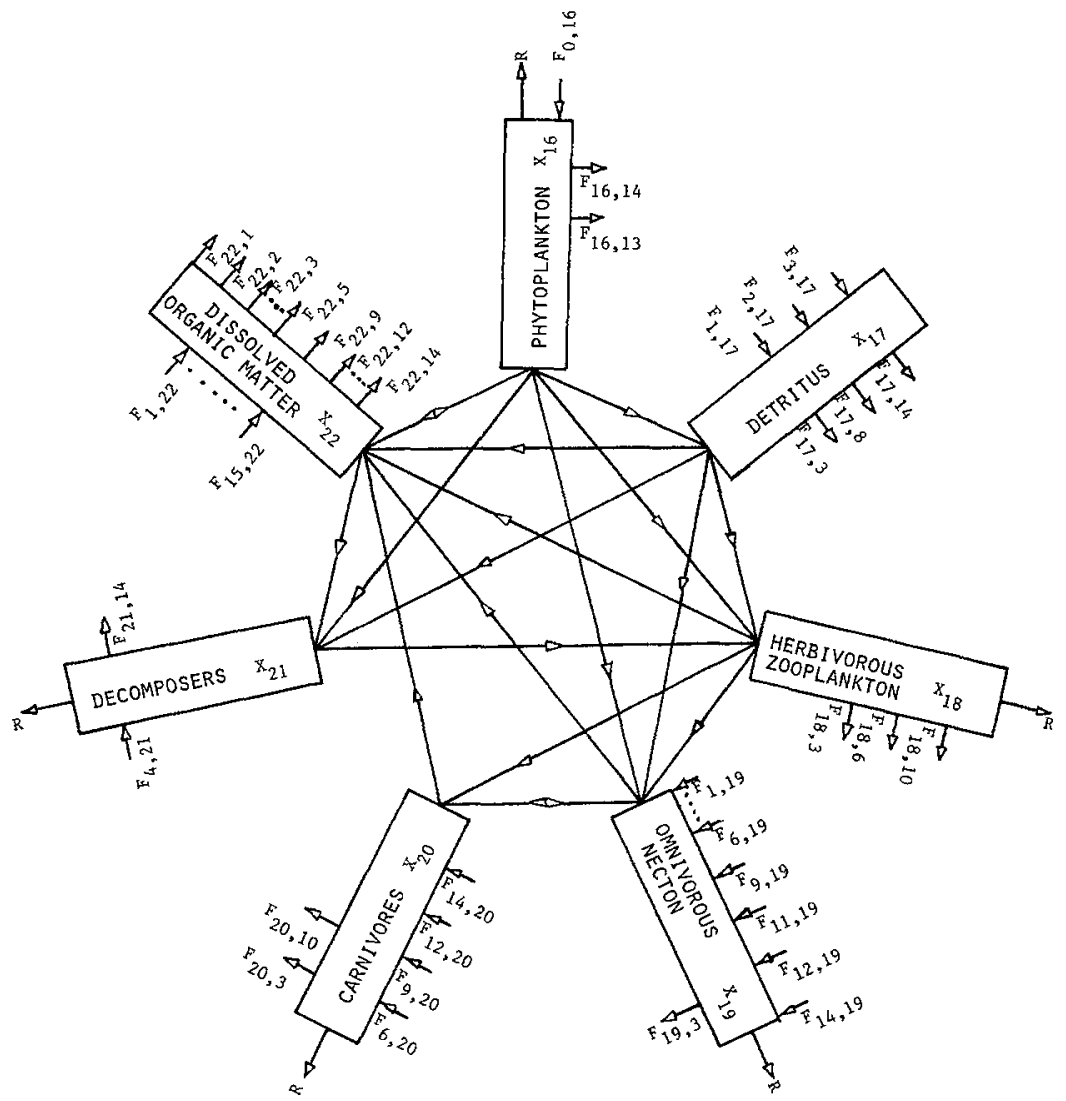

Fig. 2: The water column model

limit of the normal distribution of the fire sponge (Microcina prolifera) and the sea pansy (Renilla reniformia). The upper limit is the vegetational assemblage associated with the high tide mark. The Intertidal Zone is characterized by the presence of the following species of plants: Spartina alterniflora, S. patens, S: cynusuroides, Juncus roemerianus, Distichlis spicata, Salicornia spp., and/or Iva frutescens (Fig. 3).

(3) The benthic subtidal zone is the area beneath the water column and seaward of the lower limit of the intertidal marsh. Included in the benthic subtidal zone is the material between the sediment-water interface to a depth of $50 \mathrm{~cm}$ (Fig. 4).

The conceptual model of North Inlet is of the compartment type with the storage and flow of energy between the various compartments and the flux of energy 
into and out of the system. The variables within the model are the parameters and state variables. The parameters are forcing functions from outside the system, such as light energy and the rates of energy flux between compartments. In Figures 2-4, the parameters which enter and leave a compartment but are generated by a particular submodel are listed as $F_{i}, j$, where ${ }_{i}$ is the compartment which lost the energy and ${ }_{j}$ is

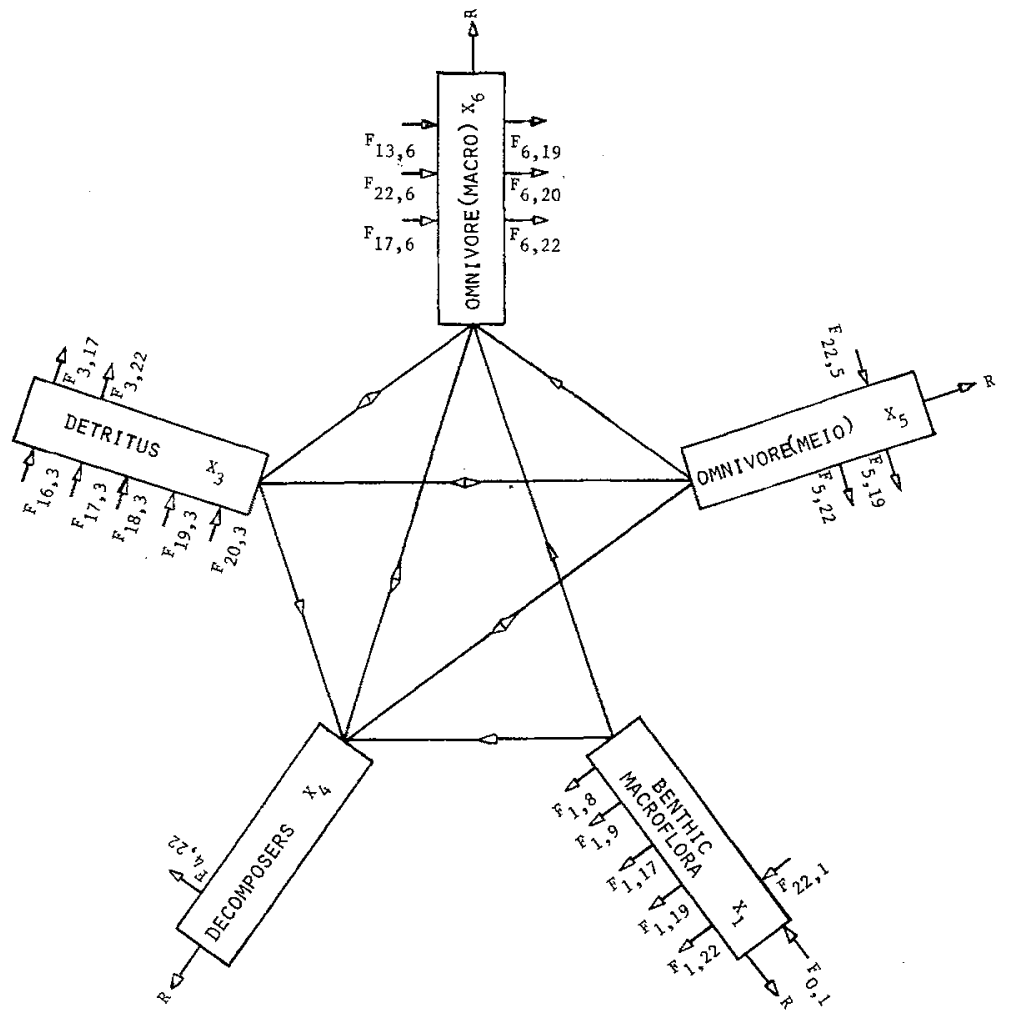

Fig. 3: The benthic subtidal model

the compartment which received the energy. The respiration parameters are shown as $R$ to indicate energy lost from the system. Relationships between compartments in a given submodel are shown by directional arrows, but these parameters may also be written as previously described. The state variables $\left(X_{j}\right)$ describe the concentration of energy in a given compartment $\left(\mathrm{kcal} \mathrm{m}^{-2}\right)$.

\section{Compartments}

The overall model consisted of the 23 compartments or state variables which are defined as follows:

$\left(\mathrm{X}_{1}\right)$ Benthic macroflora. The energy associated with those macroscopic algae, 
including filamentous forms, that are attached to a benthic substrate, but excluding those species of blue-green algae that form mats and that contribute to the stability of the benthic sediments. Primary species: Green, red and brown algae.

$\left(\mathrm{X}_{2}\right)$ Benthic microflora. The energy associated with those microscopic algae, both unicellular and multicellular that are primarily associated with the upper $1 \mathrm{~cm}$

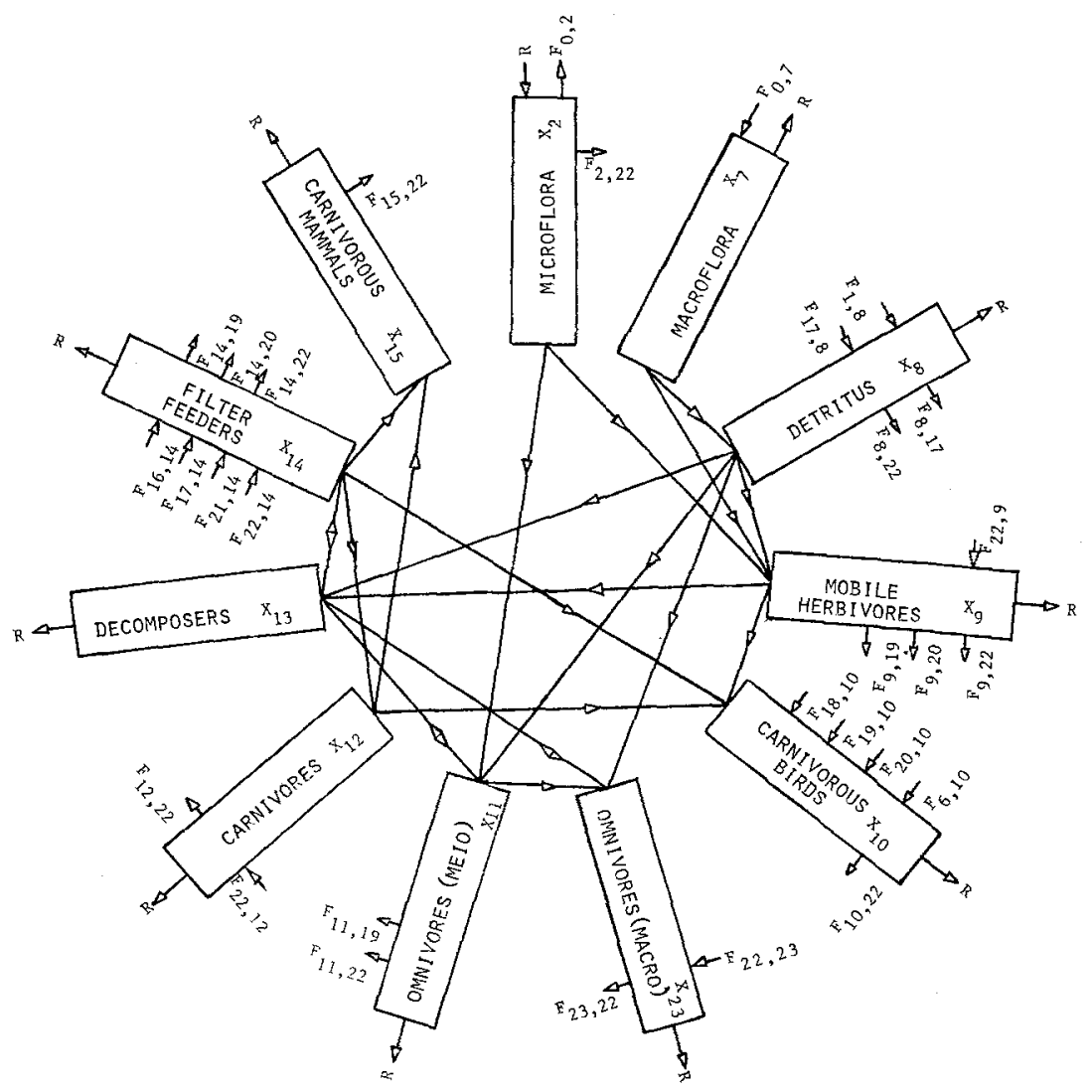

Fig. 4 : The intertidal model

of the marsh mud and sand surfaces, and including blue-green algae that form mats and contribute to the stability of the benthic sediments.

$\left(\mathrm{X}_{3}\right)$ Benthic detritus. The energy associated with the dead organic material in or on the bottom below the mean low tide, also includes dissolved organic carbon in the sediment.

$\left(\mathrm{X}_{4}\right)$ Benthic decomposers. The total microbial biomass measured using ATP. The dominant species of benthic bacterial decomposers are: Pseudomonas, Vibrio, Acbromobacter, Aeromonas, and Cytophaga.

$\left(\mathrm{X}_{5}\right)$ Omnivore-meiobenthic. The energy associated with those benthic animals living below the mean low tide that pass through a $0.5 \mathrm{~mm}$ sieve and are retained on a $0.063 \mathrm{~mm}$ sieve. 
$\left(\mathrm{X}_{6}\right)$ Omnivore-macrobenthic. The energy associated with those omnivorous benthic animals living below the mean low tide that are retained on a $0.5 \mathrm{~mm}$ sieve.

$\left(\mathrm{X}_{7}\right)$ Intertidal macroflora. The energy associated with all rooted vegetation growing in the intertidal marsh zone. The dominant species are: Spartina alterniflora, S. patens, S. cynosuroides, Juncus roemerianus, Distichlis spicata, Salicornia virginica, Salicornia sp., Iva frutescens, and Barrichia frutescens.

$\left(\mathrm{X}_{8}\right)$ Intertidal detritus. The energy associated with the plant and animal (biogenic) material decomposing in the intertidal marsh.

$\left(\mathrm{X}_{9}\right)$ Mobile intertidal herbivores. The energy associated with mobile intertidal macrofauna larger than $1 \mathrm{~mm}$ mesh which consume plant or detrital material.

$\left(\mathrm{X}_{10}\right)$ Carnivorous birds. The energy associated with all avian species, both resident and transient, that feed in the intertidal marsh or on the water column. The dominant species feeding on the water column are: Black Skimmer, Terns, Bay and Sea Ducks, Pellican, and Osprey. In the intertidal marsh: Marsh Wren, Rails, and Seaside and Sharp-tailed Sparrows.

$\left(\mathrm{X}_{11}\right)$ Intertidal omnivores (Meio). The energy associated with those benthic animals living between mean-low water and mean high water that pass through a $0.5 \mathrm{~mm}$ sieve but are retained on a $0.063 \mathrm{~mm}$ sieve.

$\left(\mathrm{X}_{12}\right)$ Intertidal carnivores. The energy associated with crabs, chiefly Panopeus, Eurypanopeus, and occasionally $U c a$, which feed upon other animals.

$\left(\mathrm{X}_{13}\right)$ Intertidal decomposers. The total microbial biomass in intertidal sediment measured using ATP. The dominant species of intertidal bacteria (decomposers) are: Pseudomonas, Vibrio, Acbromobacter, Aeromonas, and Cytophaga.

$\left(\mathrm{X}_{14}\right)$ Intertidal filter feeders. The energy associated with the intertidal macrofauna which filter microscopic plant, animal, and detrital material out of the water.

$\left(\mathrm{X}_{15}\right)$ Carnivorous mammals. The energy associated with all mammal species (exclusive of man) that feed in the intertidal marsh. The dominant species are: Raccoon, otter, feral pigs, Norway rat, rice rat, cotton rat, harvest mouse, house mouse, and deermouse.

$\left(\mathrm{X}_{16}\right)$ Phytoplankton. The energy associated with those microscopic algae, both unicellular and multicellular, that are primarily free-floating in the water column. Primary species: diatoms, dinoflagellates, and chrysoflagellates.

$\left(\mathrm{X}_{17}\right)$ Suspended detritus. Biogenic particulate organic matter suspended in the water column. The material retained on micro-fine glass fiber filters (Whatman $\mathrm{GF} / \mathrm{C}$ ) and converted to $\mathrm{CO}_{2}$ by combustion at $500^{\circ} \mathrm{C}$.

$\left(\mathrm{X}_{18}\right)$ Herbivores-zooplankton. The energy associated with those planktonic animals free floating or swimming that eat live plant material. Primarily the zooplankton but may include some fish larvae.

$\left(\mathrm{X}_{19}\right)$ Omnivorous nekton. The energy associated with the consumers that utilize both plant and animal matter as energy sources. The dominant species are: Mullet, crabs, Fundulus, and shrimp.

$\left(\mathrm{X}_{20}\right)$ Carnivorous nekton. The energy associated with the consumers that utilize herbivores, omnivores, and other carnivores in the water column as energy sources. The dominant species are: Sharks, dolphin, rays, trout, flounder, spot, croaker, drum and seaturtles. 
$\left(\mathrm{X}_{21}\right)$ Suspended decomposers. The total microbial biomass in the water column during the ebb and flood tide as $\mathrm{mg} \mathrm{C} \mathrm{m}^{-2}$ measured using ATP. The dominant species of suspended bacterial decomposers are: Pseudomonas, Vibrio, Achromobacter, Aeromonas, and Cytophaga.

$\left(\mathrm{X}_{22}\right)$ Dissolved organic matter (DOM). The energy associated with those dissolved chemicals in the water column, which are organic in nature and synthesized by biological processes. These are mainly compounds arising from excretory and secretory processes.

$\left(\mathrm{X}_{23}\right)$ Intertidal omnivores (Macro). The energy associated with intertidal macrobenthic consumers which utilize both plant and animal matter as energy sources. These organisms are mainly worms.

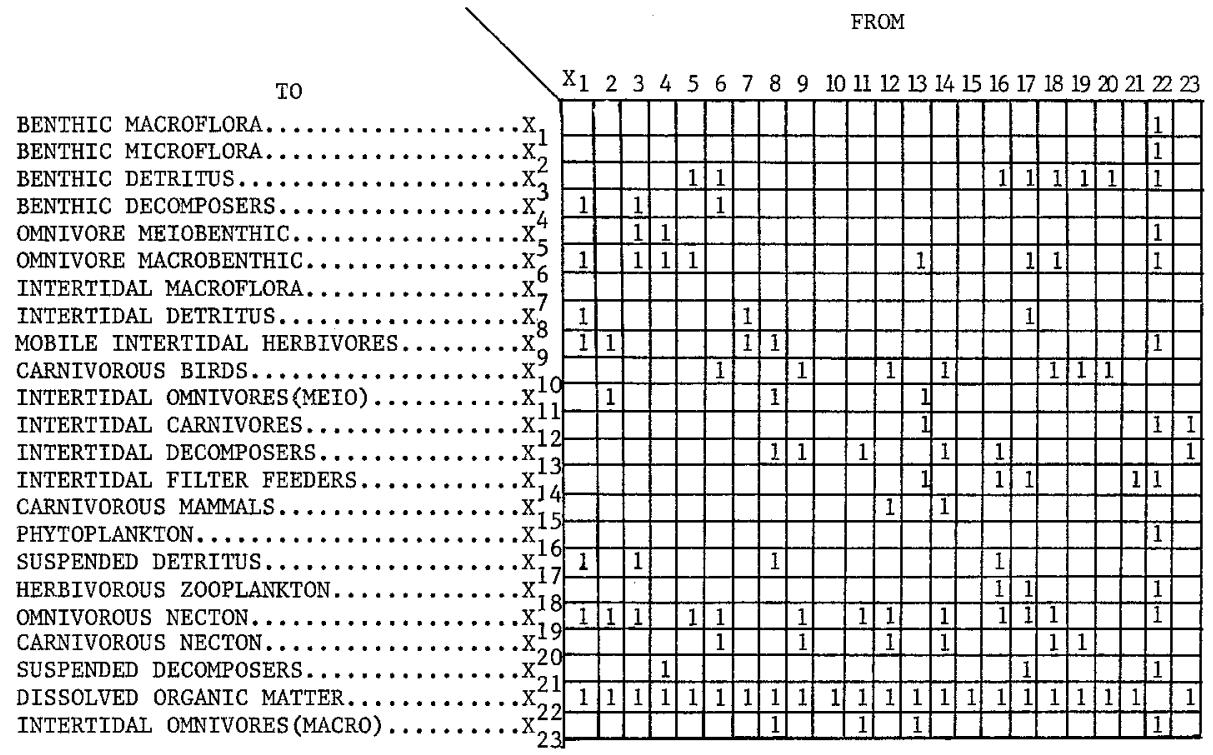

Fig. 5: The relation matrix for the total North Inlet model. A positive relation is noted with a 1

The conceptual model of North Inlet is used to illustrate data known either from direct observations or from literature sources, to visualize possible relationships, and to consider the measurability of the various rates. The relation matrix (Fig. 5) describes those interactions which we feel exist and which we are capable of estimating or measuring at this point in time. The columns of Figure 5 represent donor compartments and the rows recipient compartments. The interaction between compartments is for this model strictly energy flux. Of the 506 possible interactions in Figure $5(23 \times 23$, minus 23 because compartments do not interact with themselves), 114 have some relation. The model has a system connectivity of $23 \%$. Other ecosystem models have connectivities from less than $10 \%$ in the grass prairie model to $34 \%$ in a lake cove model (Patten, 1975a). 


\section{THE INTERTIDAL OYSTER MODEL}

We have collected data on the intertidal zone and an operational computer simulation model has been developed to describe energy flux in the intertidal oyster community. This aspect of our investigations will be described here.

Intertidal oyster communities are common to the high salinity estuarine environments of the southeastern United States. These communities are dominated by dense concentrations of oysters, Crassostrea virginica, whose shells give these assemblages a high degree of structural stability. The intertidal oyster communities are located in the mid- to low-intertidal zone and usually border or project into tidal creeks.

Studies on the intertidal oyster beds in North Inlet have been in progress since 1969 and a considerable mass of information has been accumulated on the energetics of these communities (Dame, 1972, 1976). Table 1 is a list of the average values for numbers and biomass for two years of bimonthly quantitative sampling of one particular intertidal oyster community.

Table 1

Intertidal oyster bed community and numbers

\begin{tabular}{|llrc|}
\hline Trophic level & Species & $\mathrm{m}^{-2}$ & $\mathrm{~g} \mathrm{~m}^{-2}$ \\
\hline Herbivores & Amphitrite ornata & 3 & 0.430 \\
& Brachedontes exustus & 741 & 32.330 \\
& Chione intaparpurea & 1 & 0.137 \\
& Crassostrea virginica & 974 & $164.870^{*}$ \\
& Geukensia demissus & 5 & 6.580 \\
Omnivores & Mercenaria mercenaria & 4 & $4.580^{*}$ \\
& Anurida maritima & 14 & 0.611 \\
& Gammarideans & 6 & 0.006 \\
& Heteromastus filiformis & 105 & 0.139 \\
& Insect pupae & 3 & 0.012 \\
& Marphysa sanguinea & 5 & 0.120 \\
& Melita nitada & 7 & 0.022 \\
& Nereis succinea & 102 & 0.717 \\
& Phyllodocea fragilis & 7 & 0.074 \\
Carnivores & Uca pugilator & 4 & 0.380 \\
& Eurypanopeus depressus & 61 & 5.700 \\
& Odostoma impressa & 23 & 0.061 \\
* Soft body dry weight only & 56 & 5.890 \\
& Panopeus berbstii & & \\
\hline
\end{tabular}

Since energy and energy flux are the attributes of most interest in understanding the North Inlet marsh-estuarine system, a compartment model of energy flow through our intertidal oyster community (Fig. 6) was developed. The state variables and parameters are the same as those previously described for the North Inlet conceptual model. Values for the standing crops (state variables) and rate functions (parameters) are given in Table 2.

The values in Table 2 were determined as follows: A value of $5 \mathrm{kcal} \mathrm{g}^{-1}$ was used to convert the dry weight biomass of invertebrates into standing crop energy 
(Cummings, 1967); the methodology of Dame $(1972,1976)$ was used to account for the energy retained in shells; and decomposer energy has been estimated by Stevenson (personal communication) to be $1.0 \mathrm{kcal} \mathrm{m}^{-2}$.

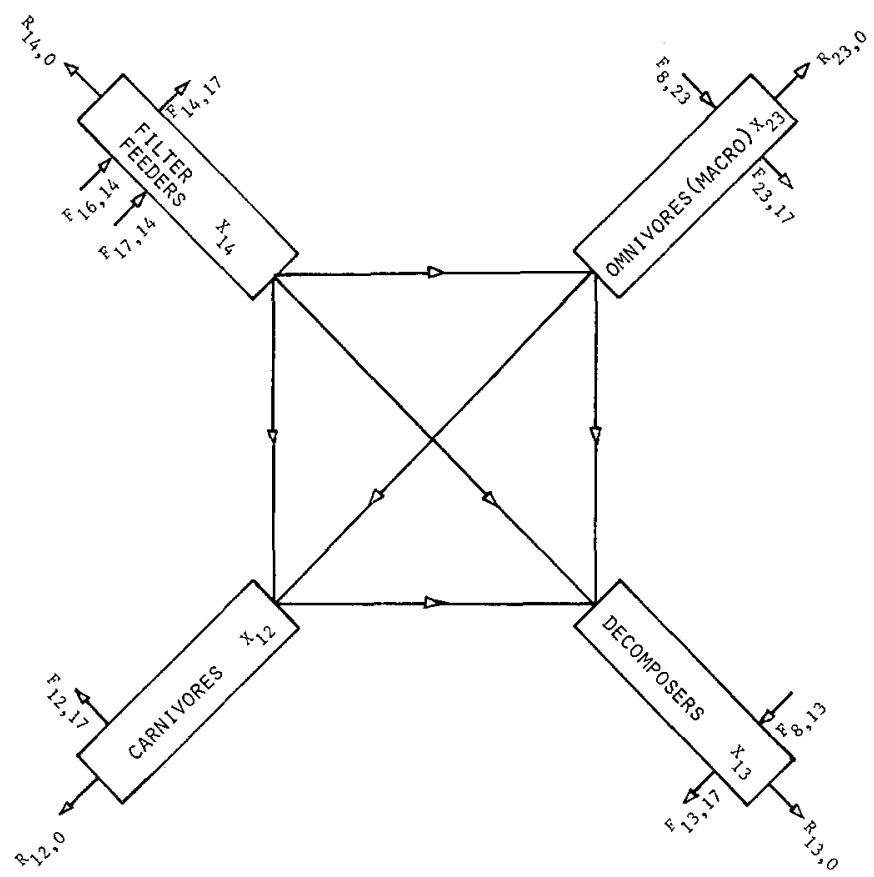

Fig. 6: The intertidal oyster community model

Seven years of observations of the intertidal oyster beds in North Inlet indicate there is little change in biomass and diversity; thus, this community appears to be stable (Dame, 1976, in prep.). From these observations it is assumed that the intertidal oyster community model is at steady state, where input equals output from the system's boundaries and for each compartment. The input to $\mathrm{X}_{14}$ from algae $\left(\mathrm{F}_{16,14}\right)$ and detritus $\left(\mathrm{F}_{17,14}\right)$ is calculated by summing the total output from $\mathrm{X}_{14}$ and setting this value equal to $\left(\mathrm{F}_{16,14}+\mathrm{F}_{17,14}\right)$. Input of detritus $\left(\mathrm{F}_{8,23}\right)$ to $\mathrm{X}_{23}$ is considered as $25 \%$ of the total input required to equal the outputs from this compartment. Little is known about the input and output from the decomposers, therefore, the input of detritus $\left(\mathrm{F}_{8,13}\right)$ to $\mathrm{X}_{13}$ was considered equal to the export $\mathrm{X}_{13}\left(\mathrm{~F}_{13,17}\right)$ to achieve a balanced model.

Respiration values were taken from the literature or calculated from equations using dry body weights. Respiration estimates for oysters and other bivalve herbivores $\left(R_{14,0}\right)$ utilize the observations of Dame (1972, unpublished). The respiration of carnivorous crabs $\left(R_{12,0}\right)$ is estimated from the observations of Dame \& Vernberg (unpublished), while values for the other macrofauna are computed using the general equation of Pamatmat (1968). Decomposer respiration $\left(R_{13,0}\right)$ was set equal to the sum of the mortality inputs to this compartment. 
Table 2

Initial values for state varibles and parameters of intertidal oyster model

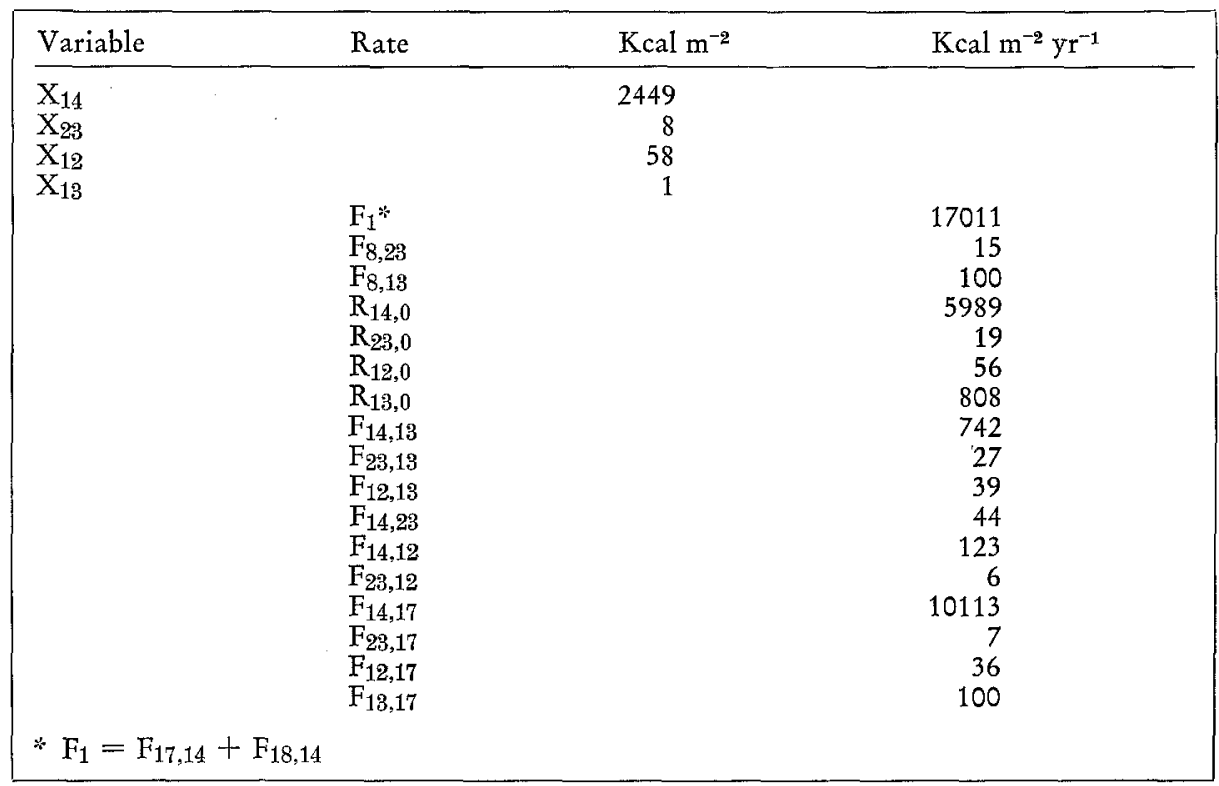

Mortality was calculated from the turnover time for a given compartment. Turnover times used were: herbivores - 3.3 years (Dame, 1976), omnivores - 0.3 years (D. M. Dauer, personal communication), and carnivores -1.5 years (Dame \& Vernberg, in prep.).

Feeding by the omnivores on the filter feeders $\left(\mathrm{F}_{14,23}\right)$ was calculated by taking $75 \%$ of the total inputs needed to balance the sum of the outputs from $\mathrm{X}_{23}$. Feeding by the carnivores on the herbivorous filter feeders $\left(\mathrm{F}_{14,23}\right)$ was found by summing the outputs from $\mathrm{X}_{12}$, taking a feeding input of $50 \%$ of the total omnivore production $\left(\mathrm{F}_{23,12}\right)$ and allowing the remainder of the required input to come from the herbivores.

Export from the system was in the form of feces, pseudofeces, and feeding by transient carnivores. Production was estimated for the various components from Dame (1976), Dame \& Vernberg (in prep.) and the general equations developed by McNeill \& Lawton (1970). Utilizing an assimilation efficiency for oysters of 0.62 (Dame, 1972), export of feces and pseudofeces was computed. The export of feces and pseudofeces from $X_{23}$ and $X_{12}$ was estimated to be $14 \%$ of the standing crop biomass of the respective compartments. $\mathrm{X}_{13}$ export was set equal to $\mathrm{X}_{13}$ input of detritus as previously stated. Predation of $\mathrm{X}_{14}$ by carnivores external to the system was found by subtracting the remainder of production. Export from $\mathrm{X}_{23}$ to transient carnivores was equated as $50 \%$ of total omnivore production. A value of $100 \%$ of the carnivore production was used as feeding by external carnivores on $\mathrm{X}_{12}$, because there are no predators on this compartment within the system's boundaries. 
The next stage in modeling a system is to develop a mathematical model which describes the amounts of energy and rate of energy flow. One typical method is to produce a set of ordinary differential equations describing the system. This type of model requires that the inputs and outputs of each compartment be expressed in the form of differential equations. For a simple linear system, such as the intertidal oyster community model, transfer coefficients are computed for the steady state by dividing the rate of energy leaving a compartment by the amount of energy contained in the compartment. The transfer coefficients for the intertidal oyster community model are shown below; the Greek letters $\varrho, \lambda, \mu$ and $\tau$ stand for respiration, export from the system, mortality to the decomposers and predation within the system respectively:

$$
\begin{array}{llll}
\varrho_{14,0}=2.44 & \lambda_{14,17}=4.13 & \mu_{14,13}=0.30 & \tau_{14,23}=0.02 \\
\varrho_{23,0}=2.36 & \lambda_{23,17}=0.86 & \mu_{23,13}=3.33 & \tau_{14,12}=0.05 \\
\varrho_{12,0}=0.95 & \lambda_{12,17}=0.58 & \mu_{12,13}=0.67 & \tau_{23,12}=0.72 \\
\varrho_{13,0}=734.70 & \lambda_{13,17}=90.91 & &
\end{array}
$$

By assuming the energy transferred from a donor compartment to a receiving compartment is directly proportional to the energy in the donor compartment, and by putting all the energy losses and gains from a compartment in terms of transfer coefficients, the system can be defined by the following set of differential equations, one equation for each compartment.

$$
\begin{aligned}
& \mathrm{dX}_{14} / \mathrm{dt}=\mathrm{F}_{1}-\mathrm{X}_{14}\left(\varrho_{14,0}+\lambda_{14,17}+\mu_{14,13}+\tau_{14,23}+\tau_{14,12}\right) \\
& \mathrm{dX}_{23} / \mathrm{dt}=\mathrm{F}_{8,23}+\tau_{14,23}\left(\mathrm{X}_{14}\right)-\mathrm{X}_{23}\left(\varrho_{23,0}+\lambda_{23,17}+\mu_{23,13}+\tau_{23,12}\right) \\
& \mathrm{dX}_{12} / \mathrm{dt}=\tau_{14,12}\left(\mathrm{X}_{14}\right)+\tau_{23,12}\left(\mathrm{X}_{23}\right)-\mathrm{X}_{12}\left(\varrho_{12,0}+\lambda_{12,17}-\mu_{12,13}\right) \\
& \mathrm{dX}_{13} / \mathrm{d} \tau=\mathrm{F}_{8,13}+\mu_{14,13}\left(\mathrm{X}_{14}\right)+\mu_{23,13}\left(\mathrm{X}_{23}\right)+\mu_{12,13}\left(\mathrm{X}_{12}\right)-\mathrm{X}_{13}\left(\varrho_{13,0}+\lambda_{13,17}\right)
\end{aligned}
$$

As previously defined, $X_{n}$ describes the standing crop energy of a given compartment and $F_{16,13}, F_{17,14}, F_{8,23}$ and $F_{8,13}$ are forcing functions for energy entering in intertidal oyster community system.

The next step in the modeling process was to solve the differential equations simultaneously utilizing Continuous Systems Modeling Program III (CSMP III) as described by Pattan (1971) on a IBM 370/165 digital computer. All compartments of the system reached steady state within 2.2 years. The herbivores $\left(\mathrm{X}_{14}\right)$ reached a steady state value of $2449.3 \mathrm{kcal} \mathrm{m}^{-2}$ at 0.225 years. The omnivores $\left(\mathrm{X}_{23}\right.$ ) became stable at 0.650 years with a standing crop of $8.0957 \mathrm{kcal} \mathrm{m}^{-2}$. The carnivores followed with a time of 2.025 years and a biomass of $58.194 \mathrm{kcal} \mathrm{m}^{-2}$. The decomposers required the most time to stabilize, 2.2 years with a value of $1.0997 \mathrm{kcal} \mathrm{m}^{-2}$. This simulation of the systems model indicates the model is very stable with caloric changes low.

In addition to simulating the model as given, it was analyzed for statistical sensitivity at steady state. In this case, sensitivity analysis means how the individual compartments will behave if a given rate function is changed $1 \%$. The results of the sensitivity analysis are shown in Table 3.

The $1 \%$ sensitivity analysis of the intertidal oyster community model shows that the standing crops of all compartments are most sensitive to changes in energy 
Table 3

The results of a $1 \%$ sensitivity analysis of the intertidal oyster model

\begin{tabular}{|cllll|}
\hline $\begin{array}{c}\text { Rate functions } \\
\text { and coefficients }\end{array}$ & $\mathrm{X}_{14}$ & & \multicolumn{3}{l}{$\begin{array}{l}\text { \% Change in standing crops } \\
\mathrm{X}_{23}\end{array}$} & $\mathrm{X}_{12}$ & $\mathrm{X}_{13}$ \\
\hline $\mathrm{F}_{1}$ & 1.000 & 0.752 & 0.977 & 0.882 \\
$\mathrm{~F}_{8,23}$ & & 0.254 & 0.011 & 0.082 \\
$\mathrm{~F}_{8,13}$ & 0.352 & & & 0.110 \\
$\varrho_{14,0}$ & 0.264 & 0.344 & 0.310 \\
$\lambda_{14,17}$ & 0.595 & 0.446 & 0.581 & 0.524 \\
$\mu_{14,13}$ & 0.044 & 0.032 & 0.043 & 0.770 \\
$\tau_{14,23}$ & 0.003 & 0.747 & 0.031 & 0.022 \\
$\tau_{14,12}$ & 0.007 & 0.005 & 0.007 & 0.006 \\
$\varrho_{22,0}$ & & 0.325 & 0.015 & 0.011 \\
$\lambda_{23,17}$ & & 0.119 & 0.005 & 0.004 \\
$\mu_{23,13}$ & & 0.046 & 0.002 & 0.002 \\
$\tau_{23,12}$ & & 0.099 & 0.041 & 0.001 \\
$\varrho_{12,0}$ & & & 0.430 & 0.018 \\
$\lambda_{12,17}$ & & & 0.263 & 0.011 \\
$\mu_{12,13}$ & & & 0.301 & 0.028 \\
$\varrho_{13,0}$ & & & & 0.879 \\
$\lambda_{13,17}$ & & & & 0.110 \\
\hline
\end{tabular}

input $\left(F_{16,14}+F_{17,14}\right)$ to the $X_{14}$ compartment. This is expected in a simple linear model. In addition, all four compartments exhibit a high level of sensitivity to changes in export $\left(\lambda_{14,17}\right)$ and respiration $\left(0_{14,0}\right)$ from $X_{14}$. All compartments are fairly sensitive to change in their respective respiration energy losses. Compartment $\mathrm{X}_{23}$, the omnivores, is also sensitive to energy losses to the decomposers $\left(\mu_{23,13}\right)$ and external to the system $\left(\lambda_{12,17}\right)$. Finally the decomposers $\left(X_{13}\right)$ are very sensitive to changes in respiration energy loss $\left(\varrho_{13,0}\right)$ and energy input from the herbivores $\left(\mu_{14,13}\right)$. Using this sensitivy analysis of the intertidal oyster community model as a guide, it is quite easy to develop a hierarchy of transfer functions for future study.

\section{DISCUSSION}

The linear systems model of the North Inlet intertidal oyster community showed only small initial fluctuations and these fluctuations ceased within 2.2 years. This response seems to describe the naturally occurring intertidal oyster communities in North Inlet which have been stable for at least the past five years. We cannot at this time say that this model is a valid representation of the "real world" intertidal oyster communities until we have manipulated and stressed existing intertidal oyster beds and simulations of the model have predicted the changes which our manipulations produce in the real communities.

The linear character of the intertidal oyster community systems model may have to be changed especially in respect to the feeding rates of the herbivores. It is obvious that despite increases in the food supply to the herbivores, beyond their needs, the herbivores will not in nature continue to grow (Tenore \& Dunstan, 1973; Winter, 1973). One possibility might be to model the herbivore feeding rates with 
some feedback repression similar to the procedure described by Wiegert (1975). Predominantly linear models of an ecosystem or community are probably unrealistic, but it should be noted that linearization may describe ecological systems in their large scale better than non-linear models (Patten, 1975b).

The development of a linear systems model of the intertidal oyster community has noted shortcomings in that there is a paucity of available data. There are no quantitative data on the export of energy from the community by transient predators, although we do know these predators exist. It is of particular importance that information be gathered on the magnitude of detritus and algae food sources available to the filter feeding herbivores since these feeding rates are very sensitive to change. The lack of information on the decomposer component standing crop and the sensitivity of decomposer respiration point to further areas of exploration.

The utilization of ecosystem models can increase man's understanding of complex natural systems and lead to more efficient research efforts through data summarization and organization. The analysis of the North Inlet marsh-estuarine ecosystem has benefitted from such an approach. We must keep in mind, that a good model is a constantly evolving entity which changes through time as man's understanding of nature increases. There is no final model.

Acknowledgements. The authors would like to acknowledge the support of grants NSF GA - 36915 and EPA - No. R - 802928. This is publication No. 163 of the Belle W. Baruch Institute for Marine Biology and Coastal Research. Drs. Bruce Coull, Pat DeCoursey, Daniel Dauer, Björn Kjerfve, Harold Stevenson, Winona Vernberg and Richard Zingmark have aided in this project. We are also indebted to the staff of the Belle W. Baruch Institute for Marine Biology and Coastal Research for their fine efforts in support of the North Inlet Ecosystem project. In addition we thank Stewart Stevens and Wilfred Zinker for their assistance. The senior author gratefully thanks the Coastal Carolina Educational Foundation for a travel grant to attend the 6th International Helgoland Symposium on 'Ecosystem Research'.

\section{LITERATURE CITED}

Cummings, K. W., 1967. Calorific equivalents for studies in ecological energetics. Pymatuning Laboratory, University of Pittsburgh, Pittsburgh, $52 \mathrm{pp}$.

Dame, R. F., 1972. The ecological energies of growth respiration and assimilation in the American oyster, Crassostrea virginica. Mar. Biol. 17, 243-250.

- 1976. Energy flow in an intertidal oyster population. Estuar. coast. mar. Sci. 4, 243-253.

McNeill, S. \& Lawton, J. H., 1970. Annual production and respiration in animal populations. Nature, Lond. 225, 472-474.

Pamatmat, M. M., 1968. Ecology and metabolism of a benthic community on an intertidal sand flat. Int. Revue ges. Hydrobiol. 53, 211-298.

Patten, B. C., 1971. Systems analysis and simulation in ecology. Acad. Press, New York, 1, $1-607$.

- 1975a. A reservoir cove ecosystem model. Trans. Am. Fish Soc. 104, 596-619.

- 1975b. Ecosystem linearization: An evolutionary design problem. In: Ecosystem analysis and prediction. Ed. by S. Levin. Society for Industrial and Applied Mathematics. Philadelphia, Pa., 182-201.

Tenore, K. R. \& Dunstan, W. M., 1973. Comparison of feeding and biodeposition of three bivalves at different food levels. Mar. Biol. 21, 190-195. 
Wiegert, R. E., 1975. Mathematical representation of ecological interactions. In: Ecosystem analysis and prediction. Ed. by S. Levin. Society for Industrial and Applied Mathematics, Philadelphia, Pa., 43-54.

Winter, J. E., 1973. The filtration rate of Mytilus edulis and its dependence on algal concentration, measured by a continuous automatic recording apparatus. Mar. Biol. 22, 317-328.

First author's address: Dr. R. Dame

Coastal Carolina College

University of South Carolina

Conway, S.C. 29526

USA 